\title{
A method to define process capability profiles from the characteristics of very small software enterprises
}

\author{
Cristiano Schwening and Marcello Thiry \\ Master Program on Applied Computer Science - LQPS Group \\ Universidade do Vale do Itajaí (UNIVALI) \\ São José, Brazil \\ crsch@engsoft.com.br, marcello.thiry@gmail.com
}

\begin{abstract}
This work presents a method for the definition of process capability profiles lined up with the specific business model of small software companies. The developed method is made up of a process, artifacts and guides that assist to obtain process profiles, considering the specific characteristics (business model, enterprise growth stage and value discipline) of each small software company. Therefore, the application of the method allows selecting a set of adjusted processes and lined up with the business model offering more objective improvement actions to a small software company. Partial results obtained during a pilot evaluation of the method in a small software company in Florianópolis/SC are also presented.
\end{abstract}

Keywords: process capability profile, software process improvement, capability model, business model, small business, very small enterprises.

\section{INTRODUCTION}

In the last years the level of knowledge and adhesion to reference models proper to the definition or improvement of the organizations software processes have raised [1]. A project for software process improvement (SPI) aims to put into practice several acts turned to the improvement of those processes having priority to the software development in the organization [6]. However, to start a project for SPI is not a usual activity, mainly for Very Small Enterprises (VSEs).

The making of an SPI initiative in those enterprises requires effort, software engineering knowledge, direct and indirect financial investment, great support from the upper board of directors, proper adaptation to the practices requested and the availability of allocation of human resources to implement it, characteristics that might be not enough in many software VSEs [8].

Besides these difficulties, when analyzed from the characteristics of the enterprise model point of view, enterprise growth stage and value discipline, the elements can be even greater, as the processes to be improved should somehow be aligned to these organizational characteristics to allow the SPI to be effective.

Although there are several perceptible in software VSEs, this article considers relevant: growth stage, business model and value discipline. The growth stage defines a set of necessities, characteristics and practices through which the organizations should develop to increase their level of maturity [13]. The business model expresses the strategic view of the enterprise, a relevant point when an SPI initiative is started [12]. And the value discipline gives guidelines related to the type of strategy aimed by the organization in order to be competitive and produce value to the clients [11].

To this set of problems, the current reference models for SPI, like CMMI-DEV [2], ABNT NBR ISO/IEC 15504 [3], MR MPS [4] e iCMM [5] do not try to supply an alignment to the organization characteristics, leaving this task to those who will execute the improvement.

However, there is a raising concern in aligning the defined processes through the reference models according to the particular characteristics of each organization [7]. In this context, the developed method allows the establishment of profiles of capacity process (PCP) giving the MPS approaches an objective systematics of process selection through objective criteria, suitable for a software VSE reality.

\section{RELATED WORKS}

Several approaches to SPI have been developed to support companies during process improvement and to help in obtaining a capability profile: MARES [8], PRO2PI [6], CMMI in Small Settings Toolkit [9], FAME [10] e COMPETISOFT [7]. These approaches aim to reduce the deficiency that the current models present in relation to the alignment to the VSEs characteristics.

In order to reduce this deficiency, the mentioned approaches sought to develop specific techniques which allow helping in analysis and comprehension of the organization goals and this way collect the largest amount of information to assist the definition of the process capability profile necessary to the VSE. 
When analyzing the techniques, it is possible to evidence in the works [8], [6], [7] and [10] the use of questionnaires, interviews or checklists to analyze the organization goals and assist the later selection of the relevant processes. In the case of the work of [9], the proposal was to use a workshop technique among the ones involved with the process improvement to present the processes and at the same time select those which were relevant.

Although they have techniques which help with the process selection, these approaches lack a systematic study that can automatize the analysis of questions related to the particular characteristics of the organization and identify more quickly and objectively the process capability profiles.

\section{The Method PCP-DEF}

\subsection{The Method Development}

The method was developed through the systematic making of research activities and application to pilot organizations. During the activities information from other related researches and also from the researcher's own knowledge and from other researchers from LQPS (Software Quality and Productivity Laboratory of the Universidade do Vale do Itajaí). The partial outcomes obtained in this activity were partially applied to the pilot organizations to evaluate the applicability of the generated concepts. This way, to the development of PCP-DEF (which stands for Process Capability Profile- Definition Method), the following steps were defined and put into practice:

- Identify the relevant variables to characterize an VSE.

- Map the practices of CMMI-DEV [2] according to the information related to the selected variables.

- Define the necessary steps for the definition of a PCP.

- Apply the concepts of previous steps in a software VSE.

- Assess the outcomes and adjust the PCP-DEF.

- Review and document the method

In the first step, the goal was to identify a set of characteristics which could be applicable to any software VSE. Many characteristics were assessed, but only three were considered relevant and present in any VSE: growth stage, business model and value discipline.

In the second step, the process areas and their respective practices of levels 2 and 3 of CMMI-DEV were mapped in relation to their association to the characteristics selected in the previous step. These mappings ere later compared to 9 PCPs that were defined as assessments of VSEs from Florianópolis, using MARES [8].

In the third step, through bibliographic research and the previous steps, it was developed the initial version of the execution process of PCP-DEF (partially described in topic 3.2 of this paper), which was assessed in step 4 aiming an initial test concerning the applicability of the defined process.

Finally, in the step 5 the detected adjustments will then be made for later use of PCP-DEF in other VSEs to assess it.

\subsection{The Method}

This paper defines a method which establishes a defined set of steps to identify a PCP. This PCP will then be able to be used in the context of an SPI approach in an organization. Besides the steps that follow the method, it is also identified a set of supporting tools to its execution (guidelines for variable selection and model practices adjustments).

Its use should preferably be associated with an SPI approach. Based on the growth stage, the business model and value discipline detected in the VSE, it is started the execution of the process which describes the defined activities in to obtain the process capability profile (PCP) that is suitable for the analyzed enterprise. The generated profile identifies the practices that the organization should reach to improve its processes, making possible an improvement directly aligned to its enterprise.

The method will be able to be used by an SPI approach in order to provide an initial PCP, headed to the enterprise's business goals, that might later be adapted by the approach. Although the final result of the method is a PCP there is no purpose in PCP-DEF to be a new SPI approach.

The figure 1 describes through a diagram the possible interrelations among the main steps and parts involved in the method execution. 


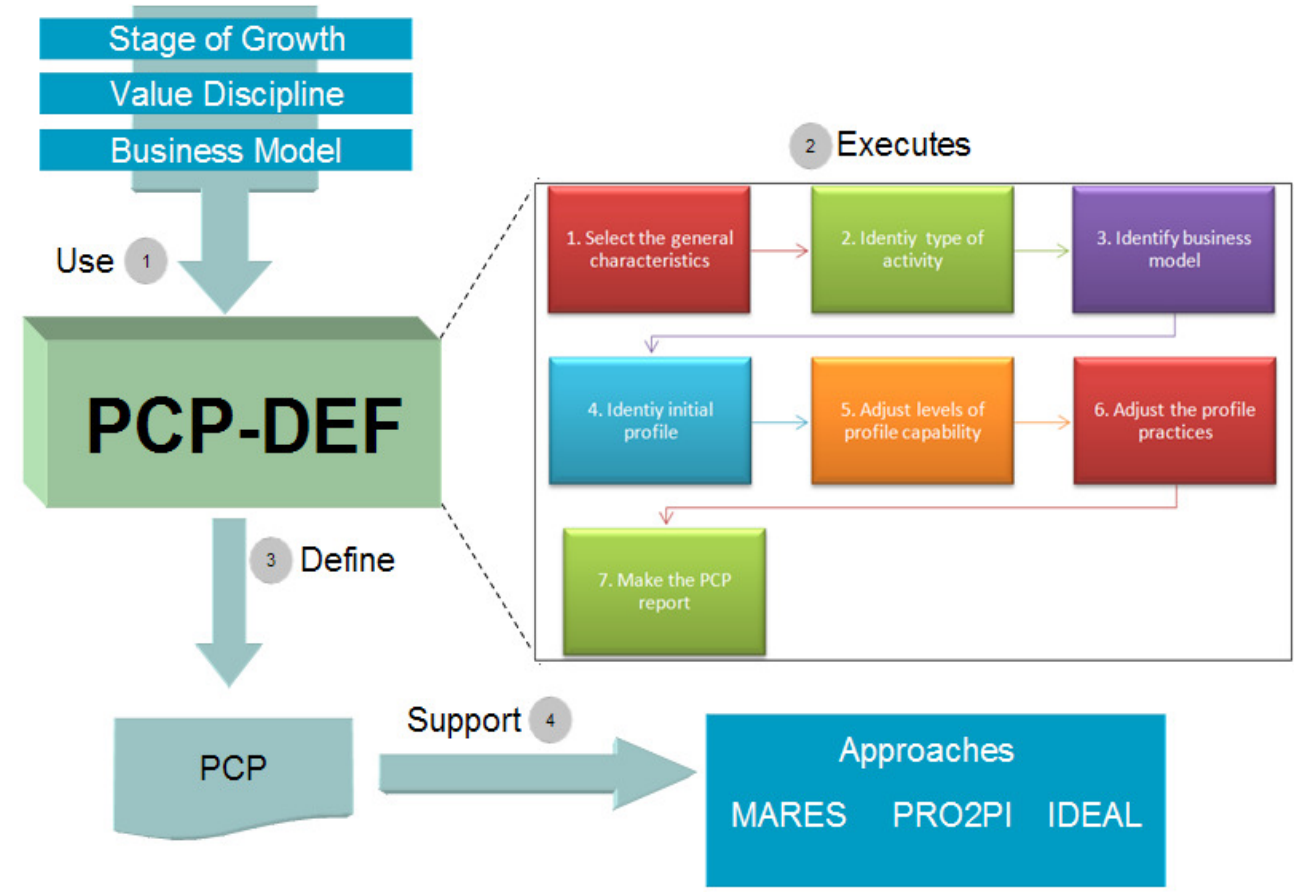

Figure 1: The usage context of the method

According to the figure 1, the use of the method starts (1) with the growth stage, value discipline and business model of the VSE previously obtained by the approach that aims to define a PCP through the method. Having this information, the method executes (2) the activities to select in the mind map the growth stage and the related value discipline; afterwards, there are several ramifications that should be explored according to the business model until reaching the final branches where it is possible to select (3) a predefined profile, that will be used as a base profile for the definition of the final PCP.

This predefined profile might suffer adjustments in its initial definition according to the characteristics of the organization business goals and using documents which guide the customization of the specific practices of each process, according to the model or standard chosen, in order to align the profile with the strategic goals of the organization.

Finally (4) a process capability profile presenting the processes is generated with the purpose of supporting the approach in the choice of the processes for the analyzed VSE. This PCP can be used in its full as a basis for a project for SPI or still suffer other adjustments proposed by the approach.

\subsection{The steps of the method}

In order to obtain the capability profile and its respective practices, a documented sequence of activities is established. These activities support and guide the professionals who execute the method, assuring the method can be systematically accomplished. The figure 2 presents the flow and the defined steps for the execution of PCP-DEF. 


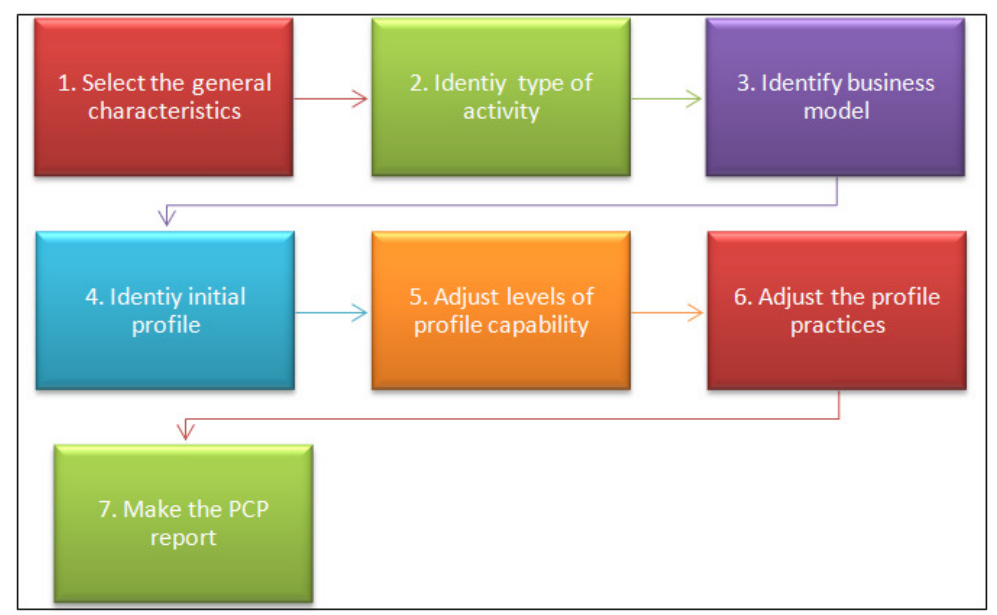

Figure 2: The usage context of the method

There is a mandatory sequence in execution of the steps as suggested in figure 2. Only step 5 could be considered not mandatory (see section 5 for further details).

As mentioned, the method initially requires the following pieces of information: The growth stage in which the company is; the business model adopted and the value discipline defined. These pieces of information must be obtained through techniques that allow the classification of the particular characteristics of the VSE according to the type of information required.

To define these pieces of information, techniques already incorporated to approaches could be used, or even traditional techniques such as questionnaires. In the case of definition of growth stage, the approach to SPI must select a level in which the VSE is at the moment of definition of PCP. In order to obtain this stage, the technique of interview could be used with the main co-workers and directors of the organization and as a whole apply directed questionnaires with questions that help in information survey. For example, the growth stage survey may contain questions that guide: according to the decision process; to the formalization; to the planning; to the hierarchy; to the attention focus; to the financial performance; to the management system; to its controls [13].

In the case of business model, for instance, questionnaires could be applied to the directors of the organization, and the questionnaire should contain the main models known in literature. Afterwards, during an interview with these people, the choice could be adjusted through a list that indicates important items of each model. The table 1 presents a set of business models known in software VSEs.

Likewise, the value discipline of the organization can be found through questions aiming the executives of the organization who seek to identify: the focus on innovation; the price policy; the relation with the customer; the quest for new borders for the product; the acknowledgement of the quality of the product by the client; the type of product delivered to the client; and to the focus on specific clients. These pieces of information can guide the selection of the value discipline which has the greater priority to the organization.

It is important to stand out that even it is not the main goal of PCP-DEF to supply objective techniques to determine the required information, the method provides checklists with the mentioned information above to detect the three required characteristics.

According to the number of characteristics to be analyzed for the definition of a PCP it was necessary to define a technique to gather this set of pieces of information, mainly in business models. The business models can be subdivided in several operation fields according to the characteristics defined by the organization, usually at the moment of the strategical definition of the organization goals.

To make possible a clear organization of these pieces of information, a concept we as defined to gather these ideas, classifying them to allow location and use. The concept adopted in this article, to induce the access to the information in a way to obtain some sort of classification was the mind map [14]. A mind map is formed by levels that are connected among themselves through lines. There is a central topic (initial level), that has connected sublevels, which can have their own sublevels in a hierarchical or tree structure. The levels form crescent stages of details and specificity, so that the initial level is more general and the sublevels more specific [14]. 
Table 1: Business Models example

\begin{tabular}{|c|c|}
\hline Business Model & Enterprise Characteristics \\
\hline $\begin{array}{l}\text { anges or } \\
\text { on (Projected) }\end{array}$ & $\begin{array}{l}\text { A customized software is built for a specific client based totally on the client's needs } \\
\text { and expectations. In this context, the new product is developed for each client, being } \\
\text { reused in some situations. The greatest problem here is that individual software is } \\
\text { implemented at high costs because it takes a long time to deliver the software. It may } \\
\text { include research in case of innovative products. In the context of the software } \\
\text { company, the requirements development may be concluded. A software product } \\
\text { developed from a requirements set obtained by the supplier from the client. }\end{array}$ \\
\hline Embedded software & $\begin{array}{l}\text { A product in which the software, although it is not explicitly perceptible to the user, } \\
\text { is a fundamental part of a piece of equipment. It is so-called for being } \\
\text { commercialized inserted in proprietor hardware, mostly designed to industrial, } \\
\text { telecommunication and bank areas. Those are the cases of embedded software's in } \\
\text { airplanes, cars and mobile phones. } \\
\text { It could be classified as embedded the software that is complex, it is installed on a } \\
\text { computer and it controls a whole environment of more sophisticated equipment. }\end{array}$ \\
\hline $\begin{array}{l}\text { Modified-off-the- } \\
\text { (MOTS) }\end{array}$ & $\begin{array}{l}\text { Customizable product, in other words it is a software package adapted by the } \\
\text { supplier to serve the specific needs of certain clients. This is a hybrid situation, as } \\
\text { normally both parts, client and supplier have to make some kind of adjustments. The } \\
\text { classical case is the business management software of the ERP type. As a } \\
\text { prerequisite for this product strategy, it must be initially developed, and then it Will } \\
\text { be modified by each new client. }\end{array}$ \\
\hline $\begin{array}{l}\text { Commercial-off-th } \\
\text { (COTS) }\end{array}$ & $\begin{array}{l}\text { Software product ready to use, that presents a set of functional characteristics and } \\
\text { quality previously defined by the supplier, to which the users get used during the use. } \\
\text { The classical cases are the suite Office, like text processors and electronic } \\
\text { spreadsheets. }\end{array}$ \\
\hline $\begin{array}{l}\text { Application Service } \\
\text { Provider (ASP) }\end{array}$ & $\begin{array}{l}\text { Software built to manage and distribute services based on software and solutions for } \\
\text { clients by remote execution through data center network: } \\
\text { - Internet/intranet based. } \\
\text { - By access or predefined cost. } \\
\text { - Integration of services to the offered products. }\end{array}$ \\
\hline Consultancy services & $\begin{array}{l}\text { Consultancy services support, in specific areas, for adjustments in a specific } \\
\text { software. }\end{array}$ \\
\hline Requirement development & $\begin{array}{l}\text { The organization hires only the requirements development, disregarding any other } \\
\text { part of the development. }\end{array}$ \\
\hline Tests & The organization hires only the tests, disregarding any other part of the development. \\
\hline System Integr & $\begin{array}{l}\text { The organization is hired only for the integration of one or more software in a } \\
\text { specific environment. }\end{array}$ \\
\hline
\end{tabular}

The following sections present an example (as figures) of PCP-DEF use through the mind map, besides describing briefly each step of the process responsible for the execution.

\subsubsection{Select the general characteristics}

This activity mainly aims to select, in the PCP-DEF document, the general characteristics related to the growth stage and the value discipline detected for the organization. In this activity, the PCP-DEF user should initially select the first sublevel (SL1) that represents the growth stage identified for the assessed organization. The next sublevel (SL2) is related to the value discipline. The figure 3 presents the part of the mind map related to both decisions. 
CLEI ELECTRONIC JOURNAL, VOLUME 13, NUMBER 1, PAPER 1, APRIL 2010

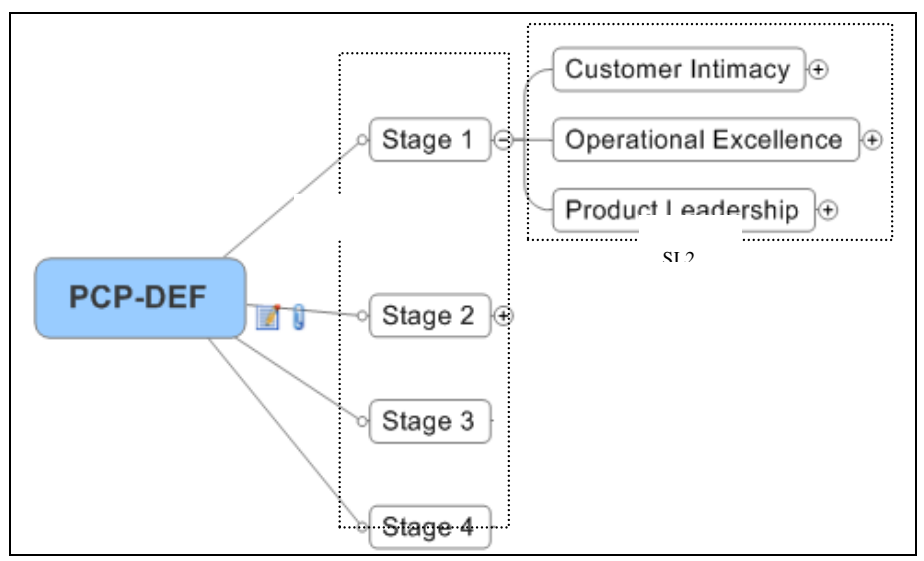

Figure 3: Select the general characteristics

In case the SPI approach does not have a proper technique to define the growth stage and value discipline, PCP-DEF proposes the use of two questionnaires for support.

\subsubsection{Identify type of activity}

This activity aims to identify the type of activity the organization develops. In this article, the organizations were classified in two great areas of operation that cover the several business models: intensive product operation and intensive service operation.

In this case it is considered product when its use can be separated from the production. In the case of a service, this can be made and consumed at the same time and place. A service can be associated to the use of a product.

In this activity, the PCP-DEF user should select, in sublevel 3 (SL3), the main (or more intensive) type of activity that the organization develops (figure 4).

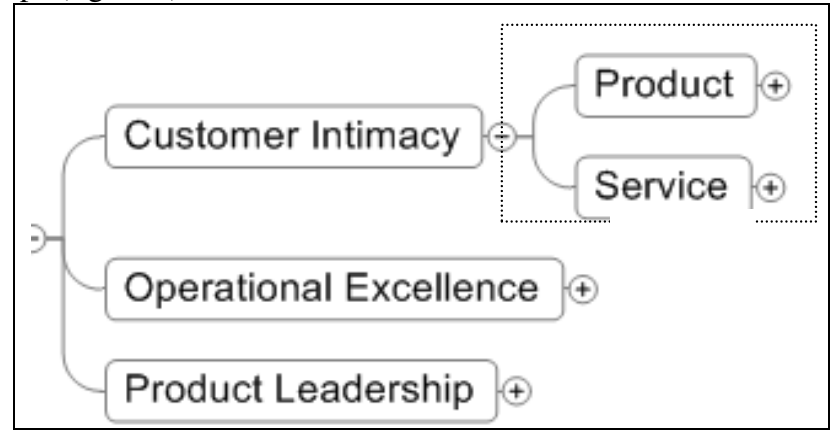

Figure 4: Identify type of activity

\subsubsection{Identify business model}

This activity aims to select the business model identified for the assessed enterprise. In several situations the organizations can adopt, strategically, more than one business model to develop their activities, but for the PCP-DEF there should be only one selected model that represents the main strategy of the organization. In case the organization has more than one business model with the same importance, it will be able to explore the PCP-DEF mind map more than once and assess the capability profile combination identified. To conclude this activity it is necessary to accomplish sublevels 4 and 5 .

The general classification of the business model of the organization must be selected from sublevel 4(SL4). If the approach for SPI does not have a technique to define the business model, the method suggests a support questionnaire. The figure 5 presents the part of mind map which allows this decision.

From the selected business model, the second step is to select, from sublevel 5 (SL5), one of the operation areas of the business model. The figure 6 presents this selection. If the approach for SPI does not have a technique to define the business model, the method suggests a support questionnaire. 
The number of sublevels related to the operation area may alter according to the type of business model identified. In this section, intending only to illustrate, only one business model was explored.

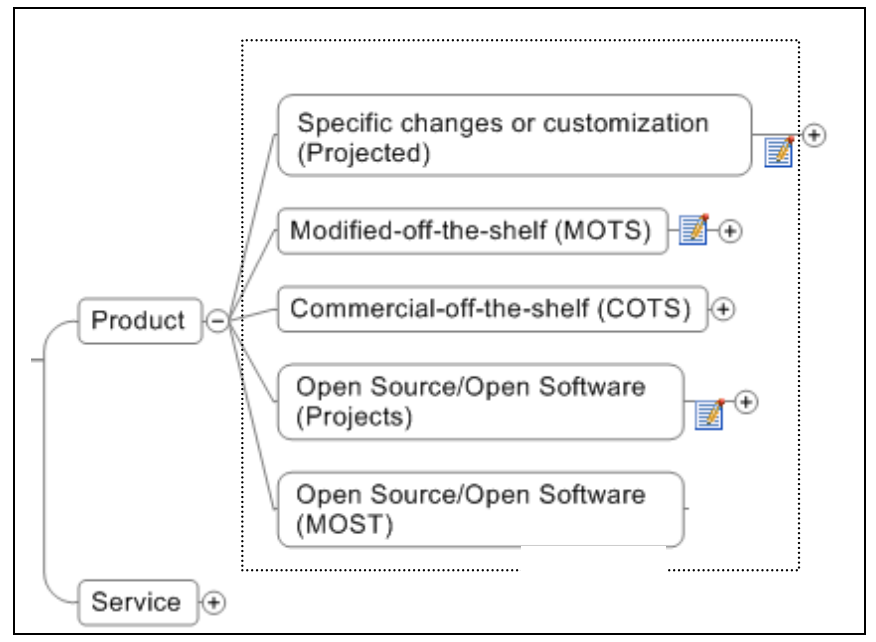

Figure 5: Identify enterprise model - Step 1

\subsubsection{Identify initial profile}

This activity aims to select the initial PCP to be used by the SPI approach. At this moment, according to the information and the steps followed until this activity it is derived a capability profile of initial processes that indicates the processes that can be treated as more relevant to the assessed organization. The PCP selected in this activity will be adjusted in accordance to criteria established in the next activity.

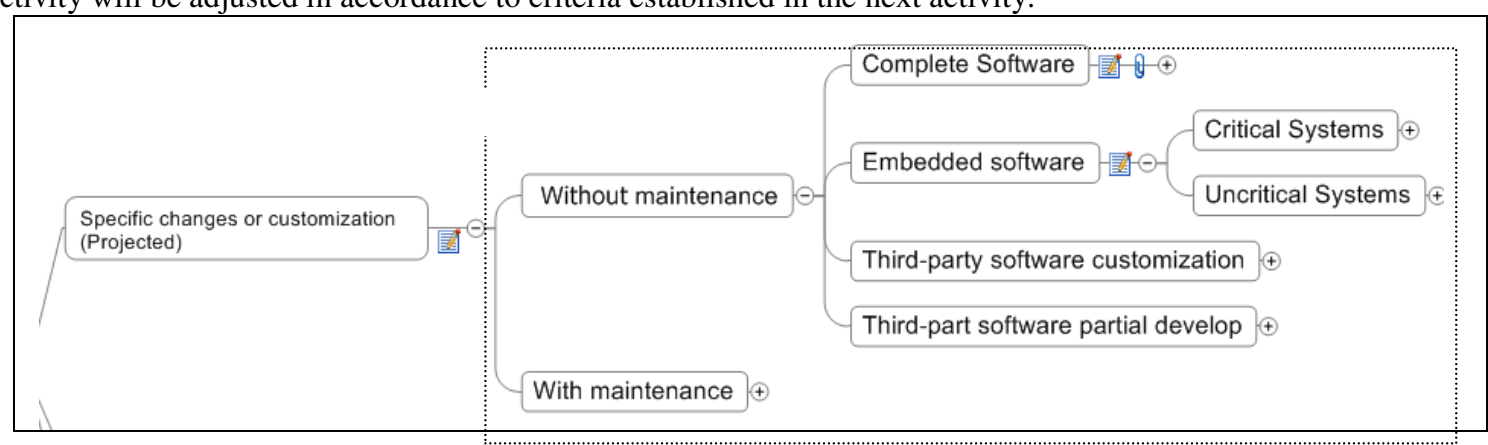

Figure 6: Identify enterprise model - Step 2

In sublevel 6 (SL6), it is presented the list of processes that form de identified PCP. This is an initial version of the PCP and it might be adjusted form the next activity of the PCP-DEF method. The figure 7 presents this decision in the mind map.

The PCP-DEF suggests a set of profiles for several business models in this last sublevel of the mind map.

These PCPs proposed by the method were defined through mappings and comparisons with other profiles produced by 12 VSEs assessments utilizing MARES. Afterwards these profiles were again adjusted using the authors' experience and also the experience of other researchers from LQPS in the field of process assessment. Some profiles also derive from definitions found in MR-MPS [4] and in the CMMI-DEV [2].

\subsubsection{Adjust levels of profile capability}

This activity aims to adjust the levels of capability of each process of the initial PCP to suit it to the level that the organization requires in relation to the selected model. This activity is mandatory in two situations:

- The organization requires an official assessment, therefore it will have the initial PCP adjusted to reflect the mandatory levels to obtain the assessment;

- Other situation, for these adjustments, would be in an organization that in some processes already has a level of capability greater than that demanded form the method. 


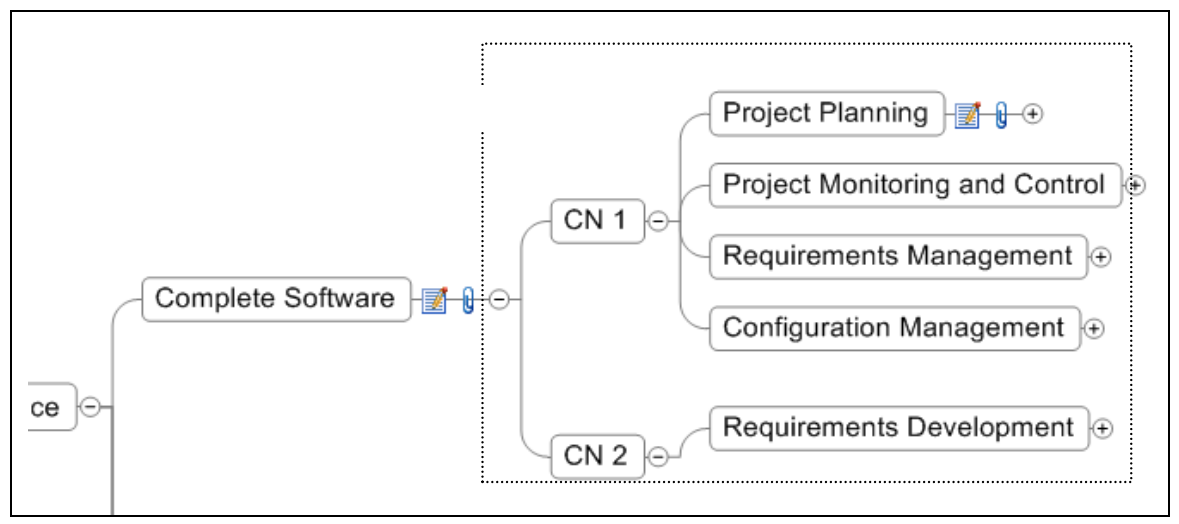

Figure 7: Identify initial profile

The user must adjust and analyze the initial PCP and find those processes that are listed initially in different levels of capability, moving them to a level where the process is mandatory.

In sublevel 7 (SL7), the levels of capability established for the identified PCP are presented. The figure 8 represents the levels of the mind map.

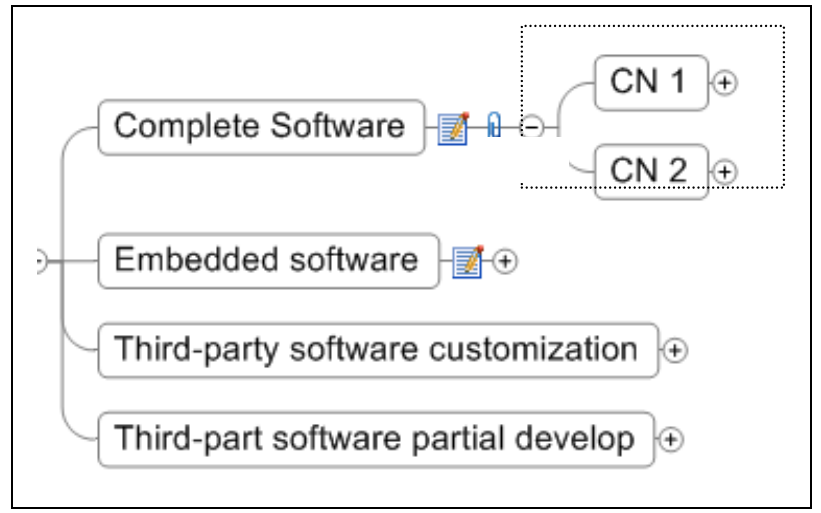

Figure 8: Adjust levels of profile capability

\subsubsection{Adjust levels of profile capability}

This activity aims to analyze in details the processes that constitute the PCP to verify the importance of each specific practice of this process for the organization. Based on the identified processes, the activity performs an analysis of the goal of each specific practice through a document named Adjustment Guide. These adjustments are performed still based on information collected by the SPI approach and on the experience of the executing team.

In order to support the adjustments in PCP , the technique of mapping the process perspectives for the organization is performed, when the financial perspectives, processes, clients, learning and growth and quality are assessed aiming to collect the presumed goals for each perspective. This mapping is important because typically, the VSEs do not own explicit knowledge upon their enterprise's goals. In sublevel 8 (SL 8) the adjustments in the project planning are presented. The figure 9 presents the level in the mind map.

This adjustment in the specific practices of the generated PCP aims to provide only those practices which are really regarded as relevant for the organization. For example, for a software company that develops product it might not be relevant a document that integrates all the plans used in a project (a project plan document) or a control of the financial resources related to the project of a version (a detailed control of the project budget).

\subsubsection{Make the PCP report}

At last, although the approach used to present the PCP-DEF in this section had been a summarized description, the method was detailed through activities using for this purpose a process representation, allowing the method to be executed systematically. 


\subsection{Example description PCP-DEF}

Table 2 describes one of the activities (section 3.3.2 of this paper). In the face of being a fraction of the processes that constitute the method, in this article it was not possible to describe in details or even to list the work products mentioned. In other words, the main goal of table 2 was to provide some details of the whole method for a better understanding.

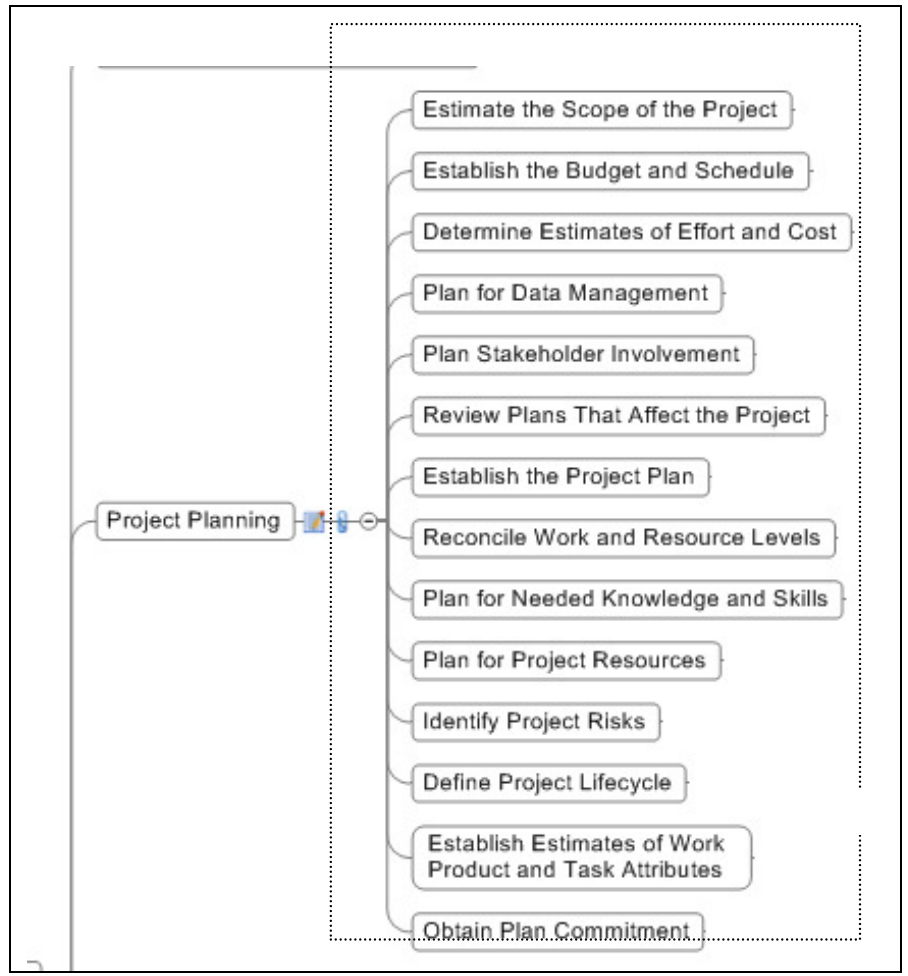

Figure 9: Adjust levels of profile capability

Table 2: Process activity example

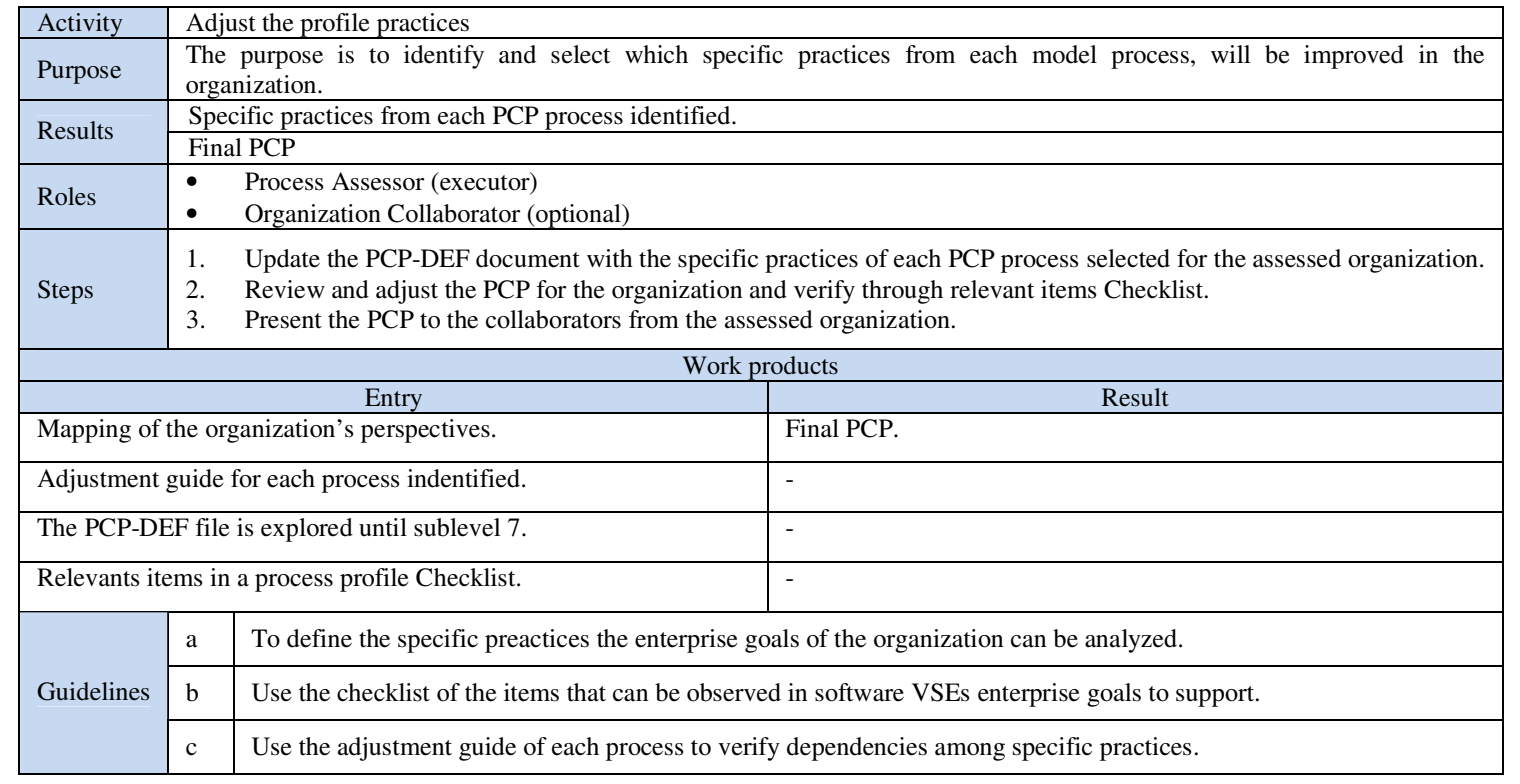




\section{ASSESSMent}

The assessment aims to analyze, in a pilot company, the process capability profile applicability. The identification of news improvements were sought, to assure a systematic application of the PCP-DEF. In this paper, the method was compared to outcomes obtained for PCPs with SPI approaches in a previous assessment. Initially, the MARES approach was used to assess the company and identify the process capability profile. It was then possible to compare results to the method application of the method developed and to obtain an analysis in relation to its alignment to the company's goals and the SPI approach.

In order to obtain a proper assessment, the use of a process can be decisive to the expected outcomes, providing a systematic and controlled way of assessing the research activities [16]. Although the defined assessment performed in this paper does not have a bias of experimentation, it follows some of the defined steps for an experiment [16]. These steps consist in definition, planning and execution, besides the analysis and interpretation of the outcomes.

Table 2 presents the outcomes of executing a pilot assessment of PCP-DEF in a VSE in Florianópolis, SC.

The first profile was produced through the execution of the activities define by the methodology of the MARES method [8], information was collected through questionnaires and meetings and the main directors and co-workers with knowledge about their software processes were interviewed. The definition of the profile presented in figure 10 was generated in a meeting with the company, by a group of 6 process assessors from UNIVALI [15]. The profile identified at that moment covered process of CMMI-DEV [2] and of ISO/IEC 15504 [3].

\begin{tabular}{|l|l|l|l|}
\hline \multirow{2}{*}{ Process Area } & \multicolumn{2}{c|}{ Capability Level } \\
\cline { 2 - 4 } & Performed & Managed & Defimed \\
\hline Project Planning(PP) & & & \\
\hline Project Monitoring andControl(PMC) & & & \\
\hline Requirements Management(REQM) & & & \\
\hline Process and Product Quality Assurance (PPQA) & & & \\
\hline Supplier Agreement Management(SAM) & & & \\
\hline Configuration Management(CM) & & & \\
\hline Measurement andAnalysis(MA) & & & \\
\hline Requirements Development(RD) & & & \\
\hline Technical Solution(TS) & & & \\
\hline Verification(VER) & & & \\
\hline Validation(VAL) & & & \\
\hline Product Integration(PI) & & & \\
\hline
\end{tabular}

Figure 10: Capability profile identified by MARES

To assess the method, the information generated during the application of the MARES method was used and described in the Final Assessment Report. The table 3 presents the characteristics detected in the assessed organization during the pilot assessment.

Table 3: Characteristics of the assessed organization

\begin{tabular}{|l|l|}
\hline Growth Stage & $\begin{array}{l}\text { SUCCESS. The organization has a defined functional structure, has good cash flow } \\
\text { capability, however concerning the organization processes, it can be considered low. }\end{array}$ \\
\hline Business Model & $\begin{array}{l}\text { MOST. The organization has a central product that is customized for each client. } \\
\text { There are frequent improvements in this central product. }\end{array}$ \\
\hline Value Discipline & $\begin{array}{l}\text { CONTACT WITH THE CLIENT. The organization, although it develops only } \\
\text { central product for all clients, is regarded for making specific customizations for each } \\
\text { client. }\end{array}$ \\
\hline
\end{tabular}

With the information described in table 3 the process capability profile was defined using the method PCP-DEF. The final profile is presented in figure 11, but in this pilot assessment only the processes related to the CMMI-DEV were analized. 
CLEI ELECTRONIC JOURNAL, VOLUME 13, NUMBER 1, PAPER 1, APRIL 2010

\begin{tabular}{|l|l|l|l|}
\hline \multicolumn{2}{|c|}{ Process Area } & \multicolumn{2}{c|}{ Capability Level } \\
\cline { 3 - 4 } & Performed & Managed & Defimed \\
\hline Project Planning(PP) & & & \\
\hline Project Monitoring andControl(PMC) & & & \\
\hline Requirements Management(REQM) & & & \\
\hline Process and Product Quality Assurance (PPQA) & & & \\
\hline Configuration Management(CM) & & & \\
\hline Measurement andAnalysis (MA) & & & \\
\hline Requirements Development(RD) & & & \\
\hline Technical Solution(TS) & & & \\
\hline Verification(VER) & & & \\
\hline Validation(VAL) & & & \\
\hline Product Integration(PI) & & & \\
\hline Organizational Process Definition(OPD) & & & \\
\hline
\end{tabular}

Figure 11: Capability profile identified by PCP-DEF

When compared to the results presented in figures 10 and 11 , it is possible to verify that the main processes required are defined in both methods (MARES and PCP-DEF). However, in the profile defined by PCP-DEF (figure 11) the Organizational Process Definition (OPD) was added. The OPD aims to provide assistance to establish and maintain a usable set of assets of organizational processes and work environment standards [2].

The justification for the inclusion of the OPD process, during the profile definition in the PCP-DEF, is related to the characteristics of the growth stage and value discipline. The PCP-DEF suggests the addition of this process, even partially. This inclusion aims to allow the organization to keep its processes adjusted to the enterprise when defining some practices, this way making possible to raise its level of growth and increase its relation with the client. Regarding the instruments and guidelines defined for the method, the execution of this pilot assessment provided the following improvement spots:

- Describe, giving more information, the steps of the process.

- Improve the quality of the mind map documents to allow the selection of the capability level automatically.

- The guidelines that support the execution of the method should be rewritten to make the text clearer.

- Standardize a format to all instruments and guidelines.

- Make quicker the process of PCP report generation, inclusively formatting a standard document.

- Centralize in one directory the necessary electronic documents for the use of the method.

Analyzing the results obtained with this pilot application of the PCP-DEF it is possible to verify that the methodology developed to select the PCP has great possibility of application together with the approaches mentioned in section 2. Although some adjustments are necessary in some points of the method, there are no reasons for its use by process assessors to be difficult.

\section{FURTHER STEPS}

This paper presents the steps related to the development of the PCP- DEF. The next actions include performing activities of adjustments detected in the instruments and guidelines and afterwards, the period of execution of the assessment in 7 software VSEs in Florianópolis/SC and Caxias do Sul/RS (both cities are from south of Brazil).

These assessments will aim to execute the PCP-DEF in VSEs to assess its applicability and effectiveness in relation to the definition of PCPs, as well as verify if these proposed profiles are aligned to the company's goals. Assessments are programmed and will take place in companies where the definition of the PCP was performed with MARES [8], allowing a comparison between both generated profiles.

In addition to this assessment with companies, the PCPs obtained by the method will be assessed by MPS.BR [4] aiming to verify if the set of processes and practices resulting are aligned to the business model of the organizations.

\section{Conclusion}

The models and standards developed usually are very generic, thus not serving to specific contexts of each organization.

On the other hand, the organizations need to consider their characteristics or establish initiatives of improvement in software processes that are aligned to its business. Seeking to attend this necessity, it was presented a method that can be used to define capability profiles focused on the processes that are more aligned to the business model of the 
organization. This capability profile is obtained through an objective set of characteristics that can be found in any type of VSE.

So far, the research could detect that the processes improvement is important for the organizations and emphasized the importance among the alignment of the processes and the strategical definitions defined by the organizations. This alignment allows the organization to add the advantages of management through processes to its particular characteristics. Analyzing the current version of the PCP-DEF, it is possible to notice its applicability to support the demands of the SPI approaches. One of the contributions of this method will be the offer of one more option of support tool to the process definition, making quicker and more objective the selection of relevant processes for an SPI project.

In relation to the results obtained in the first step of assessment it is possible to notice that the activities that guide the PCP-DEV provide a proper systematic to perform the profile definition. Although some improvement was detected, the activities and products developed for the method allow a quick execution with no need of training for its use.

This way, this article sought to show the relevance of the existence of an alignment among the definition of the set of views that represent the specific aspects of the enterprise (its characteristics) and the set of processes. And also presents a feasible option of method for the definition of this set of processes.

\section{References}

[1] MCT - Ministério da Ciência e Tecnologia. "Qualidade do setor de Software Brasileiro 2005”, Publicação eletrônica [mensagem pessoal], Mensagem recebida por <crsch@engsoft.com.br> em 18 mar. 2008.

[2] SEI - Software Engineering Institute. "CMMI for Development, Version 1.2", Carnegie Mellon University, Software Engineering Institute, Pittsburgh, 2006. Disponível em: http://www.sei.cmu.edu, verificado em Abril/2008.

[3] NBR ISO/IEC 15504-5:2008, Tecnologia da informação - Avaliação de processo Parte 5: Um exemplo de Modelo de Avaliação de Processo. Associação Brasileira de Normas Técnicas, 2008..

[4] SOFTEX - ASSOCIAÇÃO PARA PROMOÇÃO DA EXCELÊNCIA DO SOFTWARE BRASILEIRO. MPS.BR - Guia Geral:2009, maio 2009. Disponível em www.softex.br.

[5] L. Ibrahim, B. Bradford, D. Cole, L. LaBruyere, H. Leinneweber, D. Piszczek, N. Reed, M. Rymond, D. Smith, M. Virga and C. Wells, "The Federal Aviation Administration Integrated Capability Maturity Model (FAA-iCMM), Version 2.0, An Integrated Capability Maturity Model for Enterprise-wide Improvement”, Technical Report at The Federal Aviation Administration, 2001.

[6] C.F.Salviano, "Uma proposta orientada a perfis de capacidade de processo para evolução da melhoria de processo de software". Tese de doutorado pela Universidade Estadual de Campinas, Faculdade de Engenharia Elétrica e de Computação. 2006.

[7] H. Oktaba e M. Piattini, "Software process improvement for small and medium enterprises : techniques and case studies". Information Science Reference, Hershey, New York, 2008.

[8] A. Anacleto, C. G. von Wangenheim e C. F. Salviano, "Avaliação de Processos para Início de Programas de Melhoria em Micro e Pequenas Empresas de Software”. VI Simpósio Internacional de Melhoria de Processos de Software, São Paulo, 2004.

[9] S. Garcia, C. Graettinger e K. Kost, "Proceedings of the First International Research Workshop for Process Improvement in Small Settings, 2006”. Special Report CMU/SEI-2006-SR-001, Software Engineering Institute, 2006.

[10] Fraunhofer Institute Experimentelles Software Engineering, "FAME: A Business-Focused Method for Process Assessment. http://www2.iese.fraunhofer.de/fhg/iese_DE/projekte/auto_projects/assess.jsp.

[11] M. Treacy e F. Wiersema, Customer Intimacy and Other Value Disciplines, Harvard Business Review, Jan/Fev, pp. 84-93, 1993.

[12] R. Rajala, M. Rossi, V.K. Tuunainen, "A Framework for Analyzing Software Business Models”, 2003.

[13] R. L. Daft, “Organizações: teorias e projetos”, Ed. Pioneira, São Paulo, 2003.

[14] T. Buzan, “The Mind Map Book”, Ed. Penguin Books, Londres, 1996.

[15] M. Thiry, C. G. von Wangenheim, A. Zoucas. "Aplicando avaliações de contextualização em processos de software alinhados ao nível F do MR-MPS v1.2”. ProQuality (UFLA), v. 4, p. 27-33, 2008.

[16] C. Wohlin., P. Runeson, M. Höst, M. C. Ohlsson, B. Regnell, A. Wesslén, "Experimentation in software engineering: an introduction", Kluwer Academic Publishers, Norwell, 2000. 